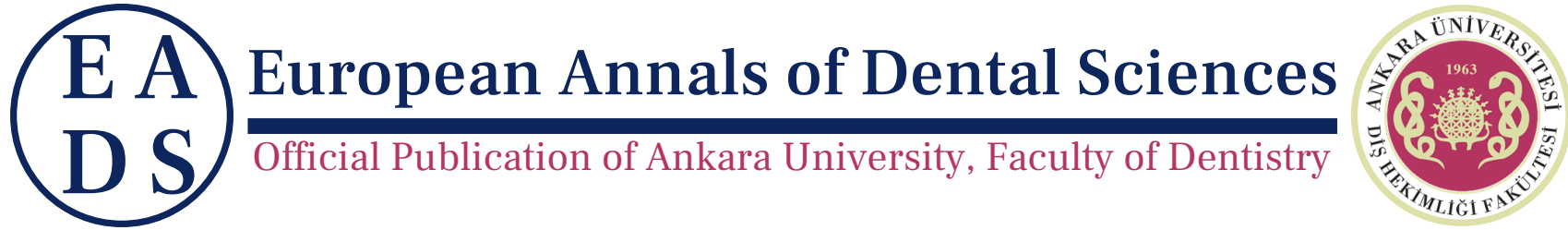

EADS, 2021, 48 (1), 1-6

\title{
Color Stability and Surface Roughness of Resin Based Direct and Indirect Restorative Materials
}

\author{
Bilge Ersöz 1,*$^{*}$, Serpil Karaoğlanoğlu ${ }^{2}$, Elif A. Oktay ${ }^{2}$ and Numan \\ Aydin 1
}

\begin{abstract}
${ }^{1}$ DDS, Department of Restorative Dentistry, University of Health Sciences, Gulhane Faculty of Dentistry, Ankara ,Turkey and ${ }^{2} \mathrm{DDS}$, PhD, Department of Restorative Dentistry, University of Health Sciences, Gulhane Faculty of Dentistry, Ankara ,Turkey

*Corresponding Author; bilgecaliskan9@gmail.com
\end{abstract}

\begin{abstract}
Purpose: This study investigated discoloration and surface roughness (Ra) of resin-based computer aided design (CAD)/computer aided manufacturing (CAM) blocks and direct and indirect resin composites after staining with coffee. Materials \& Methods: Using a Teflon mold, 60 disc shaped specimens $\left(8 \times 2 \mathrm{~mm}^{2}\right)$ were fabricated from direct (Estelite Asteria and GrandioSO) and indirect (Gradia Plus) resin composites, and 30 resin CAD/CAM specimens $\left(12 \times 14 \times 2 \mathrm{~mm}^{3}\right)$ were prepared from resin composite CAD/CAM blocks (Vita Enamic, Brilliant Crios, and Cerasmart) ( $\mathrm{n}=10$ ). A contact type profilometer was used to determine the Ra of all 60 polished samples. All specimens were thermocycled between 5 and $55^{\circ} \mathrm{C}$ for 3000 cycles, and immersed in coffee solution $\left(37^{\circ} \mathrm{C}\right)$ for 1 and 7 days. A spectrophotometer was used to determine the color change $\left(\Delta \mathrm{E}_{00}\right)$ with the CIEDE2000 formula after the specimens were re-polished. One-way analysis of variance (ANOVA) and Tukey multiple comparison test was performed to analyze the data ( $<<0.05)$. Results: The lowest degree of discoloration among the materials tested was found in Vita Enamic resin CAD/CAM block ( $p<0.001)$, whereas the highest degree of discoloration was found in the Gradia Plus indirect composite ( $<<0.001)$. There was no significant difference was seen between the initial surface roughness values $(\mathrm{Ra})$ among the groups $(\mathrm{p}=0.249)$. No significant improvement was observed in the color of the groups except for the Cerasmart resin block after after polishing. Conclusion: Direct resin composites have a higher discoloration potential over resin-based CAD/CAM blocks, whereas they are less prone to discoloration than indirect resin composites
\end{abstract}

Key words: aesthetic dentistry; discoloration; resin-based CAD/CAM materials; roughness

\section{Introduction}

A successful resin restoration should offer excellent wear resistance and simultaneously provide a satisfactory esthetic result. Despite advances in resin monomer and filler particle technology, discoloration in time in resin composites still constitutes a problem. ${ }^{1}$ Changes in the color or translucency of the restorations caused by intraoral conditions or drinks cause loss of the esthetic properties of the restorations. There are many studies on the coloring of composite materials, but there are few studies comparing the color stability properties of CAD/CAM resins and other composite materials. ${ }^{2}$ For this purpose this study aims to determine the initial surface roughness (Ra) of resin-based CAD/CAM blocks, detect changes in color after exposure to aging and the staining solution $(\Delta \mathrm{E})$, and evaluate the degree of discoloration removal after polishing.

With advances made in the field of computer aided design CAD/CAM technology, manufacturers have fabricated resin based ceramic restorative materials that combine the advantages of composites and ceramics. ${ }^{3}$ Hybrid ceramics, polymer infiltrated ceramic network materials, and resin nano ceramic materials are currently available. ${ }^{4}$ These materials, unlike ceramic restorations, do not require firing in the finishing and polishing process, and restoration can be completed in a single visit after manual polishing or light curing with resin glaze. ${ }^{5}$ Although their mechanical and esthetic properties are not as superior as ceramic restorations, ease of manufacturing and repair makes these materials preferable. ${ }^{6}$ Owing to their strong polymer crosslinks that form under high temperature and pressure, resin-based CAD/CAM blocks are considered to have su- 
perior properties over direct and indirect laboratory composites. ${ }^{7}$ However, like direct and indirect composites, these materials may be sensitive to discoloration when exposed to changes in temperature, humidity, beverages containing coloring pigments, and smoking. ${ }^{8}$ In the literature, limited number of studies have investigated discoloration and surface roughness (Ra) of resin-based CAD/CAM blocks. However, it is important to know the advantages and disadvantages of these upto-date materials compared to resin composites that are frequently used in clinical conditions. For this purpose, we investigated the color changes and the surface roughness of these materials in our study.

The null hypothesis of this study were that; there is no difference (1) between the Ra of direct and indirect resin composites and resin-based CAD/CAM blocks, (2) between the discoloration sensitivity of direct and indirect resin composites, and resin-based CAD/CAM blocks, (3) among three materials in terms of discoloration removal after polishing.

\section{Materials and Methods}

For this study, three resin-based CAD/CAM blocks 1- Vita Enamic (Vita Zahnfabrik, Bad Säckingen, Germany), 2- Brilliant Crios (Coltene/Whaledent, Langenau, Germany), 3- Cerasmart (GC, Leuven, Belgium), two direct resin composites 1- Estelite Asteria (Tokuyama Dental Corporations, Tokio, Japan), 2GrandioSO (Voco, Cuxhaven, Germany), and one indirect resin composite (Gradia Plus, GC, Leuven, Belgium) were selected. Technical characteristics of the materials and their manufacturers are shown in Table 1.

Specimen size was calculated using a power analysis program ( $\alpha=0.05$ and $\beta=0.80)$, and from each group, 10 specimens were prepared to afford a total of 60 specimens. Disc-shaped direct and indirect resin composite specimens with the diameter of $8 \mathrm{~mm}$ and the thickness of $2 \mathrm{~mm}$ were prepared using a Teflon mold ( $\mathrm{n}=10$, per group). To secure smooth composite surfaces, the specimens were polymerized for $20 \mathrm{~s}$ using a light-emitting diode curing unit (DTE LUX-E Plus, Guilin Woodpecker Medical Intrument, Guilin, Guangxi, China; 1200 $\mathrm{mW} / \mathrm{cm}^{2}$ ) over a 1-mm glass slide after placing transparent strips at the top and bottom of the Teflon mold. CAD/CAM specimens ( $n=10$, per group) of $12 \times 14 \times 2 \mathrm{~mm}^{3}$ were cut out from blocks using a diamond bladed water-cooled low speed precision cutting device (Microcut 201 High Speed Precision Cutter, Metkon, Bursa, Turkey) $(n=10)$. The specimens were then cleaned using an ultrasonic cleaning device (VGT-1740, Guang Dong, China) The all specimens were stored for $24 \mathrm{~h}$ in distilled water at $37^{\circ} \mathrm{C}$ to complete the polymerization of the composite. As per the previous studies, the water-cooled specimens were grinded using a P600-to-P1200 silicon carbide grit for 30s (Metkon; Gripo 2v Grinder-Polisher, Bursa, Turkey). The specimens were cleaned for 10min with distilled water in an ultrasonic cleaner and dried. ${ }^{9}$ The specimen thickness was determined by a digital micrometer (Marcal 16 ER, Perthen, Mahr, Germany). Additional finishing and polishing procedures were applied to the specimens. A two-step rubber polishing wheel kit (Clearfil Twist Dia, Kuraray, Tokyo, Japan) was used by applying low pressure for 20 below $10,000 \mathrm{rpm}$. The specimens were then polished using a diamond polishing paste (Diapolisher Paste; GC Dental Products Europe) and a cotton brush (Renfert GmbH, Hilzingen, Germany) at a speed of $10,000 \mathrm{rpm}$ for $15 \mathrm{~s}$ with low pressure. After polishing, the specimen thickness was measured for standardization purposes, and an average reduction of $0.15 \mathrm{~mm}$ was recorded $(2 \pm 0.15 \mathrm{~mm})$. Each tool used was replaced with a new one after every 5 specimens. After manual polishing, the specimens were cleaned in an ultrasonic cleaner with distilled water for 10min and dried. All procedures were performed by the same expert. Using a contact type profilometer, three measurements were taken from the center of each specimen to obtain Ra values after polishing (Mahr Perthometer SD 26, Perthen, Mahr, Germany). Ra values were recorded at a sample length of $1.75 \mathrm{~mm}$ with a cut-off value of 0.25 . All specimens were thermocycled between 5 and $55^{\circ} \mathrm{C}$ for 3000 cycles with $60 \mathrm{~s}$ dwell time.

As the staining agent, a coffee solution was prepared with 2 $\mathrm{g}$ of instant coffee powder dissolved in $200 \mathrm{ml}$ of distilled boiled water (Nescafé Classic; Nestlé). No cream and sugar were added to the mixture. After the coffee solution cooled down to room temperature, it was poured into opaque stainless-steel containers, and specimens were placed in the containers away from each other. To avoid physical contact, each group was placed in a completely permeable holder and the specimens were kept in a vertical position during $24 \mathrm{~h}$ for 7 days. ${ }^{10}$ The coffee solution was daily changed over 7 days. After the samples were removed from the coffee solution, they were washed with distilled water for $10 \mathrm{~s}$ and dried using an air water spray. Then the specimens were polished with two-step rubber polishing wheel kit (Clearfil Twist Dia, Kuraray, Tokyo, Japan) at a low pressure for $20 \mathrm{~s}$ below $10,000 \mathrm{rpm}$. Then the specimens were polished using a diamond polishing paste (Diapolisher Paste; GC Dental Products, Tokyo, Japan) and a cotton brush at a speed of 10,000 rpm for $15 \mathrm{~s}$ with low pressure. After this final polishing step the degree of discoloration removal in the specimens were examined with a spectrophotometer (VITA Easyshade V 4.0 ${ }^{\circledR}$; VITA Zahnfabrik, Bad Säckingen, Germany) and values were recorded.

To measure changes in color, a spectrophotometer was used before each measurement, the device was calibrated on a standard white calibration surface. Three measurements were taken for each specimen and the average values of the $\mathrm{L}^{*}, \mathrm{a}^{*}$, and $b^{*}$ data were calculated. The color differences $\left(\Delta \mathrm{E}_{00}\right)$ in the 3-dimensional $\mathrm{L}^{*}, \mathrm{a}^{*}$, and $\mathrm{b}^{*}$ color space were calculated after thermocycling, after 1 and 7 days of immersion, and after polishing, in comparison to the initial color with the CIEDE2000 formula. ${ }^{11}$

$$
\Delta E_{00}=\sqrt{\left(\frac{\Delta L^{\prime}}{K_{L} S_{L}}\right)^{2}+\left(\frac{\Delta C^{\prime}}{K_{C} S_{C}}\right)^{2}+\left(\frac{\Delta H^{\prime}}{K_{H} S_{H}}\right)^{2}+R_{T}\left(\frac{\Delta C^{\prime}}{K_{C} S_{C}}\right)\left(\frac{\Delta H^{\prime}}{K_{H} S_{H}}\right)}
$$

For this study, each $\mathrm{K}_{\mathrm{L}}, \mathrm{K}_{\mathrm{C}}$, and $\mathrm{K}_{\mathrm{H}}$ were set to 1.0. The clinically accepted 50\%:50\% color change threshold was determined at $\Delta \mathrm{E}_{00}=1.8 .^{12}$

\section{Statistical analysis}

Statistical analysis of the data was performed using the statistical software SPSS 22.0 (SPSS Inc.). Normality test (Kolmogorov-Smirnov Normality Test) was applied to the surface roughness and color change data. Parametric tests were preferred as the data showed normal distribution. Two-way analysis of variance (ANOVA) and Tukey multiple comparison method were deployed to evaluate initial Ra values, thermocycling, 1 and 7 days after immersion in the staining solution, and color change values after the polishing $(\mathrm{p}<0.05)$.

\section{Results}

No statistically significant difference was found between groups in terms of initial Ra values of direct and indirect resin composites and resin-based CAD/CAM blocks, as seen in Table $2(\mathrm{p}=0.249)$. The color changes in the direct and indirect resin composites and the resin-based CAD/CAM blocks $\left(\Delta \mathrm{E}_{00}\right)$ are shown in Figure 1. Brillant Crios $\left(\Delta \mathrm{E}_{00}=0.6\right)$ and Vita Enamic 
Table 1. Resin restorative materials used in the study.

\begin{tabular}{|c|c|c|c|c|c|c|c|}
\hline Type & Brand & Manufacture & Shade & $\begin{array}{c}\text { Batch } \\
\text { Number }\end{array}$ & Monomer & Filler & $\begin{array}{r}\text { Filler ratio } \\
(\%)\end{array}$ \\
\hline $\begin{array}{l}\text { Resin } \\
\text { composite } \\
\text { nanoceramic }\end{array}$ & Cerasmart & $\begin{array}{l}\text { GC, Leuven, } \\
\text { Belgium }\end{array}$ & $\mathrm{A} 2 \mathrm{HT}$ & 14092 & $\begin{array}{l}\text { Bis-MEPP, } \\
\text { UDMA, DMA }\end{array}$ & $\begin{array}{c}\text { Silica (20 } \\
\text { nm), barium } \\
\text { glass (300 } \\
\mathrm{nm})\end{array}$ & 71 \\
\hline $\begin{array}{l}\text { Polymer } \\
\text { infiltrated } \\
\text { ceramic } \\
\text { network } \\
\text { (PICN) }\end{array}$ & Vita Enamic & $\begin{array}{c}\text { Vita } \\
\text { Zahnfabrik, } \\
\text { Bad } \\
\text { Säckingen, } \\
\text { Germany }\end{array}$ & $2 \mathrm{M} 2$ & 39440 & UDMA,TEGDMA & $\begin{array}{c}\text { Feldspar } \\
\text { ceramic } \\
\text { enriched with } \\
\text { aluminum } \\
\text { oxide }\end{array}$ & 86 \\
\hline $\begin{array}{l}\text { Reinforced } \\
\text { resin } \\
\text { composite }\end{array}$ & Brilliant Crios & $\begin{array}{l}\text { Coltene/Whaledent, } \\
\text { Langenau, } \\
\text { Germany }\end{array}$ & A2HT & G46616 & $\begin{array}{c}\text { Cross-linked } \\
\text { methacry- } \\
\text { lates, } \\
\text { Bis-GMA, } \\
\text { BIS-EMA, } \\
\text { TEGDMA }\end{array}$ & $\begin{array}{l}\text { barium glass, } \\
\text { amorphous } \\
\text { silicia } \\
\text { particles }\end{array}$ & 71 \\
\hline $\begin{array}{l}\text { Supra-nano } \\
\text { spherical } \\
\text { hybrid } \\
\text { composite }\end{array}$ & $\begin{array}{l}\text { Estelite } \\
\text { Asteria }\end{array}$ & $\begin{array}{l}\text { Tokuyama } \\
\text { Dental } \\
\text { Corporations, } \\
\text { Tokio, Japan }\end{array}$ & $\mathrm{A} 2 \mathrm{~B}$ & W128 & $\begin{array}{c}\text { Bis- } \\
\text { GMA,UDMA, } \\
\text { Bis-MPEPP, } \\
\text { TEGDMA }\end{array}$ & $\begin{array}{c}\text { Silica- } \\
\text { zirconia } \\
\text { spherical } \\
\text { (200 nm) } \\
\text { filler, } \\
\text { composite } \\
\text { filler }\end{array}$ & 82 \\
\hline $\begin{array}{l}\text { Nano-hibrit } \\
\text { composite }\end{array}$ & Grandioso & $\begin{array}{l}\text { Voco, } \\
\text { Cuxhaven, } \\
\text { Germany }\end{array}$ & $\mathrm{A} 2$ & 1029391 & $\begin{array}{l}\text { Bis-GMA, } \\
\text { Bis-EMA, } \\
\text { TEGDMA }\end{array}$ & $\begin{array}{c}0.5-10 \mu \mathrm{m} \\
\text { particles; } 20 \\
\text { nm particles }\end{array}$ & 89 \\
\hline $\begin{array}{l}\text { Microhybrid } \\
\text { (Indirect } \\
\text { composite) }\end{array}$ & Gradia Plus & $\begin{array}{l}\text { GC, Leuven, } \\
\text { Belgium }\end{array}$ & $\begin{array}{l}\text { LE Light } \\
\text { Enamel }\end{array}$ & 190917A & $\begin{array}{c}\text { UDMA, } \\
\text { dimethacry- } \\
\text { late, }\end{array}$ & $\begin{array}{c}\mathrm{SiO}_{2}, \text { fumed } \\
\mathrm{SiO}_{2}, \mathrm{Sr} \text { and } \\
\text { lanthanoid F, } \\
\mathrm{Al} \mathrm{F} \mathrm{silicate} \\
\text { (prepolymer- } \\
\text { ized) }\end{array}$ & 71 \\
\hline
\end{tabular}

Abbreviations: Bis-EMA; ethoxylated bisphenol-A dimethacrylate, Bis-GMA; bisphenol-A diglycidylether methacrylate, Bis-MEPP; 2,2-bis (4 methacryloxypolyethoxyphenyl) propane, TEGDMA; triethylene glycol dimethacrylate, UDMA; urethane dimethacrylate, bis-MPEPP; bisphenol-A polyethoxy methacrylate.

$\left(\triangle \mathrm{E}_{00}=0.6\right)$ showed the minimum change in color after the thermocycling, and the maximum color change was seen in the Gradia Plus group $\left(\triangle \mathrm{EOO}_{00}=2.3\right)$ (Table 3).

In terms of discoloration in restorative materials after 1 and 7 days immersion in the staining solution, Vita Enamic showed the least color change among the CAD/CAM blocks. However, no significant difference was present between Vita Enamic and the other two CAD/CAM blocks, namely Brillant Crios, and Cerasmart (Figure 1) ( $p<0.001)$. After 1 and 7 days immersion, direct resin composites showed more color change than resin based CAD/CAM blocks ( $\mathrm{p}<0.001$ ), while the discoloration was less over the indirect resin composites $(\mathrm{p}<0.001)$. Among the resin composite groups, the supra-nano resin composite (Estelite Asteria) showed more color change than the nanohybrid resin composite (GrandioSO) (Table 3).

Table 2. Initial surface roughness values (Ra) of samples.

\begin{tabular}{lcc}
\hline Material & Roughness Values $($ Mean \pm SD) & $\mathrm{P}$ \\
\hline Brilliant Crios & $0.149 \pm 0.19$ & \\
Cerasmart & $0.158 \pm 0.29$ & \\
Vita Enamic & $0.151 \pm 0.12$ & 0.249 \\
Estelite Asteria & $0.165 \pm 0.38$ & \\
GrandioSO & $0.132 \pm 0.38$ & \\
Gradia Plus & $0.162 \pm 0.44$ & \\
\hline
\end{tabular}

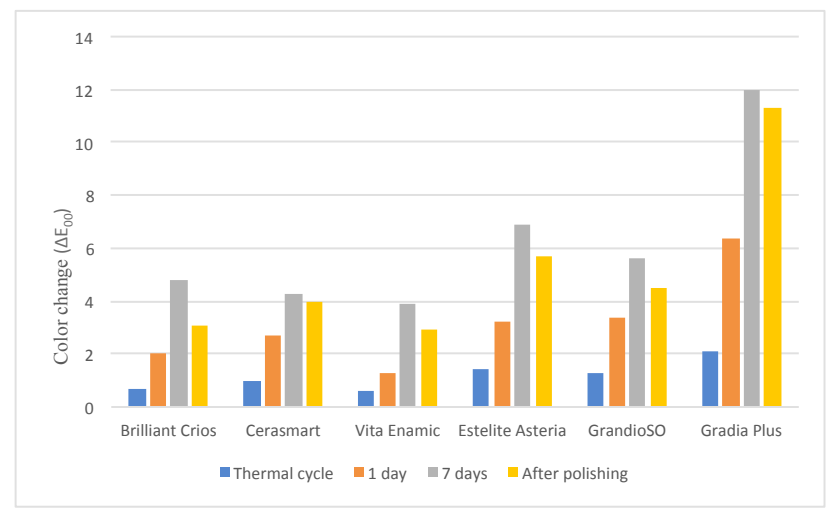

Figure 1. Color differences $\left(\Delta \mathrm{E}_{00}\right)$ of materials

Polishing led to significant color improvement in all groups except for Cerasmart $(\mathrm{p}<0.001)$. The best color correction among groups was seen for Vita Enamic and Brillant Crios, while the least color improvement was seen for Gradia Plus (Table 3). 
Table 3. Color difference $\left(\Delta \mathrm{E}_{00}\right)$ values $\left(\mathrm{Mean}_{ \pm} \mathrm{SD}\right)$ of tested materials after thermocycling, storage in coffee solution for 1 and 7 days and after polishing $\left(\Delta \mathrm{E}_{00}=1.8\right)$.

\begin{tabular}{|c|c|c|c|c|}
\hline Material & After Thermocycling & 1 Day & 7 Days & After polishing \\
\hline Brilliant Crios & $0.6 \pm 0.2^{\mathrm{a}, \mathrm{A}}$ & $1.7 \pm 0.2^{\mathrm{a}, \mathrm{B}}$ & $4.8 \pm 0.2^{\mathrm{ab}, \mathrm{C}}$ & $3.1 \pm 0.9^{\mathrm{ab}, \mathrm{D}}$ \\
\hline Cerasmart & $1 \pm 0.7^{\mathrm{ab}, \mathrm{A}}$ & $1.3 \pm 0.4^{\mathrm{ab}, \mathrm{A}}$ & $4 \cdot 3 \pm 1.1^{\mathrm{a}, \mathrm{B}}$ & $4 \pm 0.4^{b c, B}$ \\
\hline Vita Enamic & $0.6 \pm 0.4^{\mathrm{a}, \mathrm{A}}$ & $1 \pm 0.3^{\mathrm{b}, \mathrm{A}}$ & $3.9 \pm 0.2^{\mathrm{a}, \mathrm{B}}$ & $2.9 \pm 0.6^{\mathrm{a}, \mathrm{C}}$ \\
\hline Estelite Asteria & $1.3 \pm 0.2^{\mathrm{b}, \mathrm{A}}$ & $3.1 \pm 0.6^{\mathrm{c}, \mathrm{B}}$ & $6.9 \pm 0.6^{\mathrm{c}, \mathrm{C}}$ & $5.7 \pm 0.6^{\mathrm{d}, \mathrm{D}}$ \\
\hline GrandioSO & $0.7 \pm 0.1^{\mathrm{ab}, \mathrm{A}}$ & $2.3 \pm 0.4^{\mathrm{c}, \mathrm{B}}$ & $5.6 \pm 0.5^{\mathrm{b}, \mathrm{C}}$ & $4.5 \pm 0.8^{c, D}$ \\
\hline Gradia Plus & $2.3 \pm 0.5^{\mathrm{c}, \mathrm{A}}$ & $5.1 \pm 0.4^{\mathrm{c}, \mathrm{B}}$ & $12 \pm 1.1^{\mathrm{d}, \mathrm{C}}$ & $11.3 \pm 1.2^{\mathrm{e}, \mathrm{C}}$ \\
\hline
\end{tabular}

*A-D shows column comparisons, a-e shows statistical difference between lines $\mathrm{p}<0.001$.

\section{Discussion}

Since no statistically significant difference was present between the initial Ra values of the specimens, the first null hypothesis of the study was accepted. However, since resinbased CAD/CAM blocks showed less discoloration than direct and indirect resin composites, the second null hypothesis of the study was rejected. The third null hypothesis of the study was also rejected as statistically significant differences were present between the specimens in color correction after polishing.

Free radicals of monomer in resin composites the tend to react with oxygen during the polymerization of resin restorations. This results in the formation of nonreactive peroxide radicals, and an "oxygen inhibition layer" is created on the surface of the composite, which needs to be removed. ${ }^{13}$ To remove this layer, the specimens in this study were initially polished with a two-step rubber polishing wheel kit and a diamond polishing paste. The critical value for the average Ra values is $0.2 \mu \mathrm{m}$, and above this level, the bacterial colonization increases. ${ }^{14}$ In studies examining the effect of polishing systems on the surface roughness of different composites, it has been reported that there is no difference. ${ }^{15}$ Similarly, in the present study, no statistically significant difference was present between initial $\mathrm{Ra}$ among groups after polishing, and the Ra in all materials was below the critical value of $0.2 \mu \mathrm{m}$.

In this study, CIEDE2000 formula was used for color measurement before and after coloring in the colorant solutions of the samples. It has been found that the CIEDE2000 formula performed better than the CIELab formula in measuring the changes in color as perceived by the naked eye and that it is frequently preferred in clinical observation. ${ }^{16}$ According to the CIEDE2000 system, changes in color are caused by shifts in lightness, chroma, and hue, and these parameters are the most affected by thermocycling and immersion in the staining solution. Thermocycling causes hydrolytic and thermal decomposition in resin composites when they are subjected to repeated and sudden temperature changes. ${ }^{17,18}$

Tea and coffee are known to cause discoloration in dental composites. Tea is rich in tannins, and coffee contains chromogens. ${ }^{19,20}$ Previous studies have found that the average consumption time of a cup of tea or coffee is $15 \mathrm{~min} .{ }^{21}$ Assuming that an average individual consumer of tea or coffee drinks a total of three cups of either of the beverages, keeping specimens in the staining solution for 7 days will correspond to 7 months of daily consumption of these drinks in real life. In another study, different resin composite samples to thermocycling (between 5 and $55^{\circ} \mathrm{C} ; 3000$ cycles) and stored the specimens in coffee solution for 1 and 7 days. At the end of day 1, visible color change was seen on the composite samples, and the discoloration significantly increased on day 7 of immersion. ${ }^{10}$ Similarly, this study also observed significant discoloration in composite specimens after the samples were thermocycled (between 5 and $55^{\circ} \mathrm{C}, 3000$ cycles) and immersed in the coffee solution for 1 and 7 days. Similar to the results of the study, herein, samples with resin content were discolored in the coffee solution on day 1 , and the discoloration significantly increased on day $7\left(\Delta \mathrm{E}_{00}>1.8\right)$.

Furthermore, it has been found that resin-based CAD/CAM blocks are less prone to discoloration by red wine than direct and indirect resin composites. ${ }^{22}$ Similarly, in this study, resin $\mathrm{CAD} / \mathrm{CAM}$ specimens exhibited lower color change values than direct and indirect resin composites. Moreover, on day 1, for all specimens, except for resin based CAD/CAM samples, the color change values were over the acceptable threshold $\left(\Delta \mathrm{E}_{00}>1.8\right)$. On day 7 , the discoloration values for all specimen groups were higher than the acceptable threshold of $\triangle \mathrm{E}_{00}=1.8$. Lower overall discoloration values in resin-based CAD/CAM blocks can be explained by the high levels of crosslinks, reduced porosity defects, and more homogeneous polymerization of resin CAD/CAM blocks. ${ }^{22}$

No significant difference reported in $\triangle \mathrm{E}$ values of resinbased CAD/CAM blocks investigating the discoloration of resin based CAD/CAM blocks (Shofu HC Block, LavaTM -Ultimate, and Vita Enamic). ${ }^{23}$ Similarly, in this study, no significant difference was observed in color change values among resin $\mathrm{CAD} / \mathrm{CAM}$ specimens. It has been showed that the discoloration may be associated with water absorption. Water acts as a penetration vehicle for staining agents in the process of water sorption of the material, and in fact, the discoloration occurs in the first week after the contact of the restoration with water. ${ }^{24,25}$

In a study investigating two nano-hybrid fillers containing resin matrix (Cerasmart and LavaTM -Ultimate) and a polymer-infiltrated ceramic-network material (Vita Enamic); Vita Enamic exhibited the lowest degree of water absorption. ${ }^{26}$ When Vita Enamic and Cerasmart, tested together with Lava Ultimate containing Bis-GMA, Lava Ultimate showed the highest water absorption. ${ }^{27}$

Direct and indirect resin composites containing Bis-GMA show higher water absorption than those containing UDMA and TEGDMA. Most of the resin-based CAD/CAM blocks contain UDMA and TEGDMA, but not Bis-GMA. ${ }^{28}$ Therefore, we believe that high water absorption and discoloration associated with water absorption may be due to Bis-GMA. In this study, the polymer-infiltrated ceramic-network Vita Enamic, which does not contain Bis-GMA, exhibited the lowest degree of discoloration.

In a study which three resin composites tested, showed that the ones with lower filler ratio were more sensitive to discoloration. ${ }^{29}$ Similarly, in our study, the supra-nano composite Estelite Asteria ( $82 \%$ ) was colored more than the Grandioso composite ( $89 \%$ ) due to the low filler ratio. This, we believe, is due to the higher Ra value of Estelite Asteria. This shows that Ra values contribute to extrinsic discoloration. However, according to the results of the present study, the correlation between Ra values and discoloration does not hold for each and every resin material. Ra is not the only factor involved in the discoloration of resin composites; the degree of discoloration also hinges on the physicochemical properties of the 
material. ${ }^{30}$

Previous studies have shown that extrinsic discoloration of resin-based CAD/CAM materials can be reversed by an acceptable degree by finishing and polishing applications. ${ }^{31}$ It has been reported significant improvement in stain removal in $\mathrm{CAD} / \mathrm{CAM}$ blocks after polishing eight CAD/CAM blocks and four resin composites with prophylaxis paste following immersion in a coffee solution for 1 day, 1 week, and 1 mont. ${ }^{32}$ In this study, a two-step rubber polishing wheel kit and a diamond polishing paste were applied on the specimens to remove the discoloration caused by the coffee solution. A significant improvement in stain removal was observed for all the groups except for the resin-based CAD/CAM block Cerasmart. However, the discoloration was not reduced the values below the acceptable threshold of $\Delta \mathrm{E}_{00}=1.8$ in any group. Resin based CAD/CAM blocks Vita Enamic and Brillant Crios showed the best color correction, while Gradia Plus showed the lowest degree of improvement. Intrinsic discoloration in hybrid restorative materials does not penetrate as deeply as in composite materials. Therefore, hybrid resin-based CAD/CAM blocks better afforded the closest result to the initial color than the composite materials.

Today, the problem of discoloration in restorations has not been solved yet. This study was done to help choicing of materials according to the patient and personal habits. Considering the study's results, for individuals who have the habit of using coloring products such as tea, coffee, wine, and cigarettes, the use of CAD/CAM materials may be a priority when choosing materials. We can conclude that when the necessary oral hygiene is provided, the formation of external stains can be prevented to a great extent. In addition, we can conclude that the formation of extrinsic stains can be prevented to a great extent when the necessary oral hygiene is attained.

This study has some limitations. This is an in vitro study, and the staining solution contacted both sides of the specimens; moreover, the materials tested here can be considered to have simulated a Class 3 restoration, which corresponds to the largest surface area in the mouth. Future studies may be planned with longer immersion periods and longer dwell times for thermocycling.

\section{Conclusion}

Within the limitations of this study, the following conclusions can be drawn.

1. No significant difference was present between the initial roughness $(\mathrm{Ra})$ values among the groups.

2. Resin based CAD/CAM blocks were less discolored than both direct and indirect resin composites. Vita Enamic showed the lowest degree of discoloration, and Gradia Plus showed the highest discoloration.

3. After final polishing, a significant improvement was observed in all groups except for the resin-based CAD/CAM block Cerasmart.

\section{Author Contributions}

BE and NA participated in designing the study. SK and NA participated in generating the data for the study. NA and BE participated in gathering the data for the study. NA participated in the analysis of the data. BE wrote the majority of the original draft of the paper. SK, NA and EAO participated in writing the paper. All authors approved the final version of this paper.

\section{Conflict of Interest}

The authors declare no competing interests.

\section{Authors' ORCID(s)}

\author{
B.E. $\quad 0000-0003-0769-0457$ \\ S.K. $\quad 0000-0003-0601-8028$ \\ E.A.O. $0000-0003-1668-0592$ \\ N.A. $0000-0001-8628-4507$
}

\section{References}

1. Jefferies SR. Abrasive finishing and polishing in restorative dentistry: a state-of-the-art review. Dent Clin North Am. 2007;51(2):379-397, ix. doi:10.1016/j.cden.2006.12.002.

2. Stawarczyk B, Sener B, Trottmann A, Roos M, Ozcan $\mathrm{M}$, Hämmerle $\mathrm{CH}$. Discoloration of manually fabricated resins and industrially fabricated CAD/CAM blocks versus glass-ceramic: effect of storage media, duration, and subsequent polishing. Dent Mater J. 2012;31(3):377-383. doi:10.4012/dmj.2011-238.

3. Spitznagel FA, Vuck A, Gierthmühlen PC, Blatz MB, Horvath SD. Adhesive Bonding to Hybrid Materials: An Overview of Materials and Recommendations. Compend Contin Educ Dent. 2016;37(9):630-637.

4. Stawarczyk B, Awad D, Ilie N. Blue-Light Transmittance of Esthetic Monolithic CAD/CAM Materials With Respect to Their Composition, Thickness, and Curing Conditions. Oper Dent. 2016;41(5):531-540. doi:10.2341/15-252-1.

5. Lawson NC, Burgess JO. Gloss and Stain Resistance of Ceramic-Polymer CAD/CAM Restorative Blocks. J Esthet Restor Dent. 2016;28 Suppl 1:S40-45. doi:10.1111/jerd.12166.

6. Spitznagel FA, Horvath SD, Guess PC, Blatz MB. Resin bond to indirect composite and new ceramic/polymer materials: a review of the literature. J Esthet Restor Dent. 2014;26(6):382-393. doi:10.1111/jerd.12100.

7. Giordano R. Materials for chairside CAD/CAM-produced restorations. J Am Dent Assoc. 2006;137 Suppl:14s-21s. doi:10.14219/jada.archive.2006.0397.

8. Papadopoulos T, Sarafianou A, Hatzikyriakos A. Colour stability of veneering composites after accelerated aging. Eur J Dent. 2010;4(2):137-142.

9. Arocha MA, Basilio J, Llopis J, Di Bella E, Roig M, Ardu $\mathrm{S}$, et al. Colour stainability of indirect CAD-CAM processed composites vs. conventionally laboratory processed composites after immersion in staining solutions. J Dent. 2014;42(7):831-838. doi:10.1016/j.jdent.2014.04.002.

10. Koc-Vural U, Baltacioglu I, Altinci P. Color stability of bulkfill and incremental-fill resin-based composites polished with aluminum-oxide impregnated disks. Restor Dent Endod. 2017;42(2):118-124. doi:10.5395/rde.2017.42.2.118.

11. Luo MR, Cui G, Rigg B. The development of the CIE 2000 colour-difference formula: CIEDE2000. Color Research \& Application. 2001;26(5):340-350. doi:10.1002/col.1049.

12. Paravina $\mathrm{RD}$, Ghinea $\mathrm{R}$, Herrera $\mathrm{LJ}$, Bona $\mathrm{AD}$, Igiel $\mathrm{C}$, Linninger $M$, et al. Color difference thresholds in dentistry. J Esthet Restor Dent. 2015;27 Suppl 1:S1-9. doi:10.1111/jerd.12149.

13. Rueggeberg FA, Margeson DH. The effect of oxygen inhibition on an unfilled/filled composite system. J Dent Res. 1990;69(10):1652-1658. doi:10.1177/00220345900690100501.

14. Erkli H, Ersöz E. Farklı flor jellerin rezin materyallerin 
yüzey pürüzlülüğü üzerine etkisinin karşılaştırılması. GÜ Diş Hek Fak Derg. 2012;29(2):79-85.

15. Da Costa J, Ferracane J, Paravina RD, Mazur RF, Roeder L. The effect of different polishing systems on surface roughness and gloss of various resin composites. J Esthet Restor Dent. 2007;19(4):214-224; discussion 225-226. doi:10.1111/j.1708-8240.2007.00104.X.

16. Gómez-Polo C, Portillo Muñoz $M$, Lorenzo Luengo MC, Vicente P, Galindo P, Martín Casado AM. Comparison of the CIELab and CIEDE2000 color difference formulas. J Prosthet Dent. 2016;115(1):65-70. doi:10.1016/j.prosdent.2015.07.001.

17. Geurtsen W, Leyhausen G, Garcia-Godoy F. Effect of storage media on the fluoride release and surface microhardness of four polyacid-modified composite resins ("compomers"). Dent Mater. 1999;15(3):196-201. doi:10.1016/s0109-5641(99)00034-2.

18. Souza RO, Ozcan M, Michida SM, de Melo RM, Pavanelli CA, Bottino MA, et al. Conversion degree of indirect resin composites and effect of thermocycling on their physical properties. J Prosthodont. 2010;19(3):218-225. doi:10.1111/j.1532-849X.2009.00551.x.

19. Reddy PS, Tejaswi KL, Shetty S, Annapoorna BM, Pujari SC, Thippeswamy HM. Effects of commonly consumed beverages on surface roughness and color stability of the nano, microhybrid and hybrid composite resins: an in vitro study. J Contemp Dent Pract. 2013;14(4):718-723. doi:10.5005/jpjournals-10024-1390.

20. Ren YF, Feng L, Serban D, Malmstrom HS. Effects of common beverage colorants on color stability of dental composite resins: the utility of a thermocycling stain challenge model in vitro. J Dent. 2012;40 Suppl 1:e48-56. doi:10.1016/j.jdent.2012.04.017.

21. Noie F, O'Keefe KL, Powers JM. Color stability of resin cements after accelerated aging. Int $\mathrm{J}$ Prosthodont. 1995;8(1):51-55.

22. Mainjot AK, Dupont NM, Oudkerk JC, Dewael TY, Sadoun MJ. From Artisanal to CAD-CAM Blocks: State of the Art of Indirect Composites. J Dent Res. 2016;95(5):487-495. doi:10.1177/0022034516634286.

23. Quek SHQ, Yap AUJ, Rosa V, Tan KBC, Teoh KH. Effect of staining beverages on color and translucency of
CAD/CAM composites. J Esthet Restor Dent. 2018;30(2):E9e17. doi:10.1111/jerd.12359.

24. Dietschi D, Campanile G, Holz J, Meyer JM. Comparison of the color stability of ten new-generation composites: an in vitro study. Dent Mater. 1994;10(6):353-362. doi:10.1016/0109-5641(94)90059-0.

25. Schulze KA, Marshall SJ, Gansky SA, Marshall GW. Color stability and hardness in dental composites after accelerated aging. Dent Mater. 2003;19(7):612-619. doi:10.1016/s0109-5641(03)00003-4.

26. Egilmez F, Ergun G, Cekic-Nagas I, Vallittu PK, Lassila LVJ. Does artificial aging affect mechanical properties of CAD/CAM composite materials. J Prosthodont Res. 2018;62(1):65-74. doi:10.1016/j.jpor.2017.06.001.

27. Ekici MA, Egilmez F, Cekic-Nagas I, Ergun G. Physical characteristics of ceramic/glass-polymer based CAD/CAM materials: Effect of finishing and polishing techniques. J Adv Prosthodont. 2019;11(2):128-137. doi:10.4047/jap.2019.11.2.128.

28. Sideridou ID, Karabela MM. Sorption of water, ethanol or ethanol/water solutions by light-cured dental dimethacrylate resins. Dent Mater. 2011;27(10):10031010. doi:10.1016/j.dental.2011.06.007.

29. Sarafianou A, Iosifidou S, Papadopoulos T, Eliades G. Color stability and degree of cure of direct composite restoratives after accelerated aging. Oper Dent. 2007;32(4):406-411 doi:10.2341/06-127.

30. Barakah HM, Taher NM. Effect of polishing systems on stain susceptibility and surface roughness of nanocomposite resin material. J Prosthet Dent. 2014;112(3):625-631. doi:10.1016/j.prosdent.2013.12.007.

31. Liebermann A, Spintzyk S, Reymus $M$, Schweizer E, Stawarczyk B. Nine prophylactic polishing pastes: impact on discoloration, gloss, and surface properties of a CAD/CAM resin composite. Clin Oral Investig. 2019;23(1):327-335. doi:10.1007/s00784-018-2440-z.

32. Lauvahutanon $S$, Shiozawa $M$, Takahashi $H$, Iwasaki N, Oki $M$, Finger WJ, et al. Discoloration of various CAD/CAM blocks after immersion in coffee. Restor Dent Endod. 2017;42(1):9-18. doi:10.5395/rde.2017.42.1.9. 